\title{
Promoter hypermethylation of cancer-related genes: a strong independent prognostic factor in acute lymphoblastic leukemia
}

\author{
Jose Roman-Gomez, Antonio Jimenez-Velasco, Juan A. Castillejo, Xabier Agirre, Manuel Barrios, German Navarro, \\ Francisco J. Molina, Maria J. Calasanz, Felipe Prosper, Anabel Heiniger, and Antonio Torres
}

Promoter hypermethylation plays an important role in the inactivation of cancerrelated genes. This abnormality occurs early in leukemogenesis and seems to be associated with poor prognosis in acute lymphoblastic leukemia (ALL). To determine the extent of hypermethylation in ALL, we analyzed the methylation status of the CDH1, p73, p16, p15, p57, NES-1, DKK-3, CDH13, p14, TMS-1, APAF-1, DAPK, PARKIN, LATS-1, and PTEN genes in 251 consecutive ALL patients. A total of $77.3 \%$ of samples had at least 1 gene methylated, whereas $35.9 \%$ of cases had 4 or more genes methylated. Clinical features and complete remission rate did not differ among patients without methylated genes, patients with 1 to 3 methylated genes (methylated group A), or patients with more than 3 methylated genes (methylated group B). Estimated disease-free survival (DFS) and overall survival (OS) at 11 years were $75.5 \%$ and $66.1 \%$, respectively, for the nonmethylated group; $37.2 \%$ and $\mathbf{4 5 . 5 \%}$ for methylated group $A$; and $9.4 \%$ and $7.8 \%$ for methylated group B
( $P<.0001$ and $P=.0004$, respectively). Multivariate analysis demonstrated that the methylation profile was an independent prognostic factor in predicting DFS $(P<.0001)$ and OS $(P=.003)$. Our results suggest that the methylation profile may be a potential new biomarker of risk prediction in ALL. (Blood. 2004;104: 2492-2498)

๑) 2004 by The American Society of Hematology

\section{Introduction}

Cytogenetic studies in acute lymphoblastic leukemia (ALL) reveal a wide variety of translocations involving this disease; these translocations can either (1) deregulate an intact gene by disruption or removal and replacement of the adjacent controlling elements or (2) create a new fusion gene. ${ }^{1-2}$ Chromosome translocation is clearly an important oncogenic step in ALL, and structurally altered genes play key roles in cell proliferation, differentiation, apoptosis, and gene transcription. Although these molecular abnormalities may serve as diagnostic and prognostic markers, they are detectable only at low rates in specific morphologic subtypes of ALL. ${ }^{1-2}$ Furthermore, oncogenes and tumor-suppressor genes that are frequently altered in solid tumors, such as $p 53$ or $R A S$, are infrequently mutated in ALL. ${ }^{3}$ In addition to these genetic changes, epigenetic silencing of tumor-related genes, due to hypermethylation, has recently emerged as one of the pivotal alterations in cancer development. ${ }^{4-6}$

In the mammalian genome, methylation takes place only at cytosine bases that are located $5^{\prime}$ to guanosine in a $\mathrm{CpG}$ dinucleotide. $^{4-6}$ This dinucleotide is actually underrepresented in much of the genome, but short regions of 0.5 to $4 \mathrm{~kb}$ in length, known as $\mathrm{CpG}$ islands, are rich in $\mathrm{CpG}$ content. Most $\mathrm{CpG}$ islands are found in the proximal promoter regions of almost half of the genes in the human genome and are, generally, unmethylated in normal cells. In cancer, however, the hypermethylation of these promoter areas is the most well-recognized epigenetic change to occur in tumors; it is found in virtually every type of neoplasm and is associated with the inappropriate transcriptional silencing of genes. ${ }^{4-6}$ Thus, aberrant methylation serves as an alternative mechanism of gene inactivation in neoplasia, and surprisingly, such promoter hypermethylation is at least as common as the disruption of classic tumorsuppressor genes in human cancer by mutation or deletion and possibly more common.

In addition, promoter hypermethylation and transcriptional repression of functionally important cancer-related genes may also affect tumor behavior, creating an impact on clinical outcomes. Epigenetic silencing of genes that determine tumor invasiveness, growth patterns, and apoptosis, in particular, may dictate tumor recurrence after treatment and affect overall survival. Because each tumor may harbor multiple genes susceptible to promoter hypermethylation, individual tumors would exhibit different frequencies of hypermethylation profile potentially predictive of a patient's clinical outcome. ${ }^{7-8}$

Although several reports concerning methylation of different genes in ALL have been published, in most cases the methylation status has been investigated for just a single gene or in a small number of patients with short follow-up. We and others have identified several methylated genes in ALL, including CALCA, ER, MDR1, THBS2, MYF3, p15, p16, p73, p57, and CDH1. ${ }^{9-15}$ Moreover, methylation patterns may have clinical implications in ALL in that $C A L C A, p 15, p 57$, and $p 21$ methylation were found to be
From the Hematology Department, Reina Sofia Hospital, Cordoba, Spain; Hematology Department, Carlos Haya Hospital, Malaga, Spain; Hematology Department, Cellular Therapy Area, Clinica Universitaria/School of Medicine, Foundation for Applied Medical Research, University of Navarra, Pamplona, Spain.

Submitted March 12, 2004; accepted May 18, 2004. Prepublished online as Blood First Edition Paper, June 15, 2004; DOI 10.1182/blood-2004-03-0954.

Supported by grants from Fondo de Investigaciones Sanitarias (FIS; Spain) (PI030141, 01/0013-01, 01/F018, and 02/1299); Navarra goverment (31/2002);
RETIC (C03/10); Junta de Andalucia (03/143; 03/144); and funds from Cajamar-Fundacion Hospital Carlos Haya (Malaga, Spain).

Reprints: Jose Roman-Gomez, Hematology Department, Reina Sofia Hospital, Avda. Menendez Pidal s/n, 14004 Cordoba, Spain; e-mail: peperosa@teleline.es.

The publication costs of this article were defrayed in part by page charge payment. Therefore, and solely to indicate this fact, this article is hereby marked "advertisement" in accordance with 18 U.S.C. section 1734

(C) 2004 by The American Society of Hematology 
associated with dismal outcome. ${ }^{11-15}$ However, it is unclear whether methylation of these genes are prognostic because of their own regulating functions or because they reflect a distinct pathway of tumorigenesis in ALL, with distinct expression profiles of genes that could influence prognosis as a consequence of the simultaneous methylation of multiple loci. To study this issue further, we have examined multiple key cancer genes undergoing epigenetic inactivation in a large set of de novo ALLs with the aim of obtaining a map of this alteration in the disease and its possible correlation with clinical features and patient outcome.

\section{Patients, materials, and methods}

\section{Patients}

We studied 251 consecutive patients ( 151 male, 100 female) who received a diagnosis of de novo ALL between January 1990 and December 2002. The median age at diagnosis in the study population as a whole was 14 years (range, 0.5-82 years). Of these patients, 124 were children (median age, 5 years; range, 0.5-14 years), and 127 presented adult ALL (median age, 29 years; range, 15-82 years). Informed consent was obtained from the patient or the patient's guardians. Diagnosis was established according to standard morphologic, cytochemical, and immunophenotypic criteria. Patients were studied at the time of initial diagnosis; were risk-stratified according to the therapeutic protocol used, which was always based on recognized prognostic features (including cytogenetics); and were entered in ALL protocols of the Programa para el estudio y tratamiento de las hemopatias malignas (PETHEMA) Spanish study group. For statistical analyses, children were also grouped according to the National Cancer Institute (NCI) riskclassification criteria. ${ }^{16}$ The specific PETHEMAALL treatment protocols in which these patients were entered included ALL-89 (between 1990 and 1993; $\mathrm{n}=51$ ) and ALL-93 (between 1993 and 2002; $\mathrm{n}=200$ ). The design and results of these studies have been previously reported. ${ }^{17-20}$ Relapse occurred in 104 patients. Forty-four patients received stem cell transplants (14 autologous, 30 allogeneic) in the first $(n=20)$ or second $(n=24)$ complete remission (CR). There are 139 patients currently alive. Clinical characteristics of the patients are listed in Table 1 .

\section{Gene selection}

High-molecular weight DNA and total RNA were prepared from mononuclear marrow cells at the time of diagnosis with the use of conventional methods. In all the cases, the diagnostic bone marrow sample contained at least $70 \%$ blast cells. We studied 15 genes belonging to all of the molecular pathways involved in cell immortalization and transformation: cell cycle ( $p 15, p 16$, and $p 57)$; cell adherence and metastasis process $(C D H 1$ and CDH13); $p 53$ network ( 14 and $p 73$ ); apoptosis (TMS1, APAF-1, and $D A P K)$; cellular senescence (DKK-3); differentiation regulation (NES-1); ubiquitylation (PARKIN); and main tumor-suppressor genes (LATS-1 and $P T E N)$. Different criteria were used for gene selection. $C D H 1, p 73, p 16$, p15, p57, NES-1, and DKK-3 were selected because of their frequent methylation in ALL. ${ }^{9-11,15,21-22}$ CDH13, p14, TMS1, APAF-1, DAPK, PARKIN, LATS-1, and PTEN were studied because they have been found to be methylated in other malignancies, and their abnormal expression could have potentially important roles in $\mathrm{ALL}^{23-30}$ (Table 2). The regions where these genes reside are not prone to mutations, deletions, or rearrangement in the majority of human leukemias; however, microsatellite markers from these regions have shown that most of them are common sites for loss of heterozygocity in ALL. ${ }^{31}$ Each of these genes possesses a $\mathrm{CpG}$ island in the $5^{\prime}$ region, which is normally unmethylated in corresponding normal tissues as expected for a typical $\mathrm{CpG}$ island. We and others have shown, in previous studies for such genes in individual tumor types, that when these $\mathrm{CpG}$ islands are hypermethylated in cancer cells, expression of the corresponding gene is silenced and the silencing can be partially relieved by demethylation of the promoter region..$^{9-11,15,21-30}$ For all these genes, we have analyzed at least 10 normal marrow and peripheral blood specimens, none of which showed significant methylation.
Table 1. Clinical characteristics and outcomes of 251 patients by methylation profile

\begin{tabular}{cccc}
\hline & Nonmethylated & Methylated & Methylated \\
group, & group A, & group B, \\
Feature & $n=57, \%$ & $n=104, \%$ & $n=90, \%$
\end{tabular}

\begin{tabular}{|c|c|c|c|}
\hline & & & \\
\hline \multicolumn{4}{|l|}{ Age $^{*}$} \\
\hline Younger than 15 years & 61 & 46 & 45 \\
\hline Older than 15 years & 39 & 54 & 55 \\
\hline Sex, M/F & $56 / 44$ & $60 / 40$ & $63 / 37$ \\
\hline \multicolumn{4}{|l|}{ WBC count* } \\
\hline Lower than $50 \times 10^{9} / \mathrm{L}$ & 76 & 75 & 63 \\
\hline \multicolumn{4}{|l|}{ Higher than } \\
\hline $50 \times 10^{9} / \mathrm{L}$ & 24 & 25 & 37 \\
\hline \multicolumn{4}{|l|}{ FAB classification } \\
\hline L1 & 38 & 40 & 25 \\
\hline L2 & 50 & 56 & 64 \\
\hline L3 & 12 & 4 & 11 \\
\hline \multicolumn{4}{|l|}{ Blast lineage } \\
\hline B & 88 & 76 & 64 \\
\hline $\mathrm{T}$ & 12 & 24 & 36 \\
\hline \multicolumn{4}{|l|}{$\mathrm{NCl}$ risk group } \\
\hline Standard & 80 & 76 & 65 \\
\hline Poor & 20 & 24 & 35 \\
\hline \multicolumn{4}{|l|}{ PETHEMA risk group } \\
\hline Standard & 40 & 47 & 34 \\
\hline Poor & 60 & 53 & 66 \\
\hline \multicolumn{4}{|l|}{ Treatment } \\
\hline PETHEMA 89 & 20 & 21 & 20 \\
\hline PETHEMA 93 & 80 & 79 & 80 \\
\hline BMT & 14 & 17 & 20 \\
\hline Best response, CR & 91 & 93 & 88 \\
\hline \multicolumn{4}{|l|}{$\begin{array}{l}\text { Cytogenetic/molecular } \\
\text { abnormalities }\end{array}$} \\
\hline$B C R / A B L$ & 21 & 20 & 12 \\
\hline $4(1 ; 19)$ & 4 & 2 & 2 \\
\hline $11 q 23$ & 3 & 3 & 3 \\
\hline C-Myc & 6 & 3 & 8 \\
\hline $7 q 35-14 q 11$ & 6 & 6 & 5 \\
\hline Hyperdiploidy & 9 & 6 & 5 \\
\hline TEL-AML1 & 5 & 16 & 18 \\
\hline None & 42 & 39 & 40 \\
\hline Others & 3 & 3 & 3 \\
\hline NT & 1 & 2 & 2 \\
\hline Relapse† & 17 & 51 & 59 \\
\hline Death $\ddagger$ & 28 & 43 & 61 \\
\hline
\end{tabular}

Methylated group $\mathrm{A}$ indicates patients with 1,2 , or 3 methylated genes; methylated group $B$, patients with more than 3 methylated genes.

WBC indicates white blood cell; FAB, French-American-British; $\mathrm{NCI}$, National Cancer Institute; PETHEMA, Programa para el estudio y tratamiento de las hemopatias malignas; BMT, bone marrow transplantation; CR, complete remission; and NT, not tested.

${ }^{*} P=.09$.

$\dagger P<.0001$.

$\ddagger P<.001$.

\section{Methylation-specific PCR (MSP)}

Aberrant promoter methylation of these genes was determined by the MSP method as reported by Herman et al. ${ }^{32}$ MSP distinguishes unmethylated alleles of a given gene on the basis of DNA sequence alterations after bisulfite treatment of DNA, which converts unmethylated, but not methylated, cytosines to uracils. Subsequent polymerase chain reaction (PCR) using primers specific to sequences corresponding to either methylated or unmethylated DNA sequences was then performed. Primer sequences of each gene for the unmethylated and methylated reactions have been reported elsewhere.9-11,15,21-30 "Hot-start" PCR was performed for 30 cycles; this consists of denaturation at $95^{\circ} \mathrm{C}$ for 1 minute, annealing at $60^{\circ} \mathrm{C}$ for 1 minute, and extension at $72^{\circ} \mathrm{C}$ for 1 minute, followed by a final 7 -minute extension for all primer sets. The products were separated by 
Table 2. Genes studied for methylation in ALL

\begin{tabular}{|c|c|c|c|}
\hline Gene & Location & Function & Reference for MSP primers \\
\hline NES-1 & $19 q 13$ & Growth and differentiation control; putative TSG & Roman-Gomez et $\mathrm{al}^{21}$ \\
\hline LATS-1 & $6 q 23-25$ & TSG; G - -M cell cycle control; apoptosis regulation & Hisaoka et al ${ }^{29}$ \\
\hline $\mathrm{CDH} 1$ & $16 q 22$ & TSG; calcium-dependent cell-cell adhesion & Melki et al ${ }^{10}$ \\
\hline $\mathrm{CDH} 13$ & $16 q 24$ & Calcium-dependent cell-cell adhesion & Roman-Gomez et al ${ }^{23}$ \\
\hline p16 & $9 p 21$ & TSG; $\mathrm{G}_{1}-\mathrm{S}$ cell cycle control & Wong et al ${ }^{11}$ \\
\hline$A P A F-1$ & $12 q 23$ & Apoptosis regulation & Fu et $\mathrm{al}^{26}$ \\
\hline$D K K-3$ & $11 \mathrm{p} 15$ & $\begin{array}{r}\text { Wnt/catenin signaling pathway antagonist; } \\
\text { mortalization-related gene; putative TSG }\end{array}$ & Roman-Gomez et $\mathrm{al}^{22}$ \\
\hline p15 & $9 p 21$ & $\mathrm{G}_{1}-\mathrm{S}$ cell cycle control; putative TSG & Wong et $\mathrm{al}^{11}$ \\
\hline PARKIN & $6 q 25-27$ & E3 ubiquitin ligase; putative TSG & Cesari et $\mathrm{al}^{28}$ \\
\hline PTEN & 10q23 & $\begin{array}{l}\text { TSG; cell adhesion/motility; apoptosis; angiogenesis; } \\
\text { G }_{1} \text { cell cycle regulation; signal transduction }\end{array}$ & Zysman et $\mathrm{al}^{30}$ \\
\hline p57 & $11 \mathrm{p} 15$ & $\mathrm{G}_{1}-\mathrm{S}$ cell cycle control; putative TSG & Shen et al ${ }^{15}$ \\
\hline p73 & $1 \mathrm{p} 36$ & $\mathrm{G}_{1}-\mathrm{S}$ cell cycle control; putative TSG & Kawano et al ${ }^{9}$ \\
\hline$D A P K$ & $9 q 34$ & Apoptosis regulation & Katzenellenbogen et $\mathrm{al}^{27}$ \\
\hline TMS-1 & $16 \mathrm{p} 11-12$ & Apoptosis regulation & Conway et $\mathrm{al}^{25}$ \\
\hline p14 & $9 p 21$ & Cell cycle control; apoptosis regulation & Esteller et $\mathrm{al}^{24}$ \\
\hline
\end{tabular}

MSP indicates methylation-specific polymerase chain reaction; TSG, tumor suppressor gene; E3, early region 3.

electrophoresis on $2 \%$ agarose gel. Bone marrow DNA from healthy donors was used as negative control for methylation-specific assays. Human male genomic DNA universally methylated for all genes (Intergen, Purchase, $\mathrm{NY}$ ) was used as a positive control for methylated alleles. Water blanks were included with each assay. The presence of a clearly visible band in the MSP using primers for the methylated alleles was considered a positive result for methylation. This result was always confirmed by repeat MSP assays after an independently performed bisulfite treatment. In the sporadic cases where only faint bands were observed in both analyses, methylation results were validated by Southern blot, sequencing, and/or association with lack of expression assessed by reverse-transcription PCR (RT-PCR) as appropriate. The sensitivity of this MSP was established by using totally methylated, positive control DNA serially diluted by normal lymphocyte DNA. MSPs with positive control DNA diluted in ratios of 1:10, 1:100, and 1:1000 produced detectable methylated bands (data not shown).

\section{Other molecular analyses}

Standard Southern blot method was employed to detect immunoglobulin heavy-chain gene rearrangement and T-cell receptor- $\beta$ rearrangement. The $11 \mathrm{q} 23$ abnormalities were studied with the B859 probe kindly provided by Dr G. Cimino (Rome, Italy). ${ }^{33}$ The $p 210^{B C R-A B L}$, p190 ${ }^{B C R-A B L}$, and TELAML1 fusion transcripts were detected by means of the reverse transcriptionpolymerase chain reaction according to the primers and protocols established by the European BIOMED 1 concerted action. ${ }^{34}$

\section{Statistical analysis}

For statistical purposes, ALL patients were classified into 2 different methylation groups: nonmethylated (no methylated genes) and methylated (at least one methylated gene). The methylated group was also divided into 2 other groups according to the number of methylated genes observed in each individual sample: methylated group A (1 to 3 methylated genes) and methylated group B (more than 3 methylated genes). $P$ values for comparisons of continuous variables in groups of patients were 2-tailed and were based on the Wilcoxon rank sum test. $P$ values for dichotomous variables were based on the Fisher exact test. The remaining $P$ values were based on the Pearson chi-square test. Overall survival (OS) was measured from the day of diagnosis until death from any cause and was censored only for patients known to be alive at last contact. Disease-free survival (DFS) was measured from the day that CR was established until either relapse or death without relapse, and it was censored only for patients who were alive without evidence of relapse at the last follow-up. Distributions of OS and DFS curves were estimated by the method of Kaplan and Meier, with 95\% confidence intervals calculated by means of Greenwood's formula. Comparisons of groups by OS or DFS were based on the log-rank test. Comparisons adjusted for significant prognostic factors were based on Cox regression models and hazard regression models. All relapse and survival data were updated on December 2003, and all follow-up data were censored at that point.

\section{Results}

\section{Frequency of methylation in ALL}

Among 251 ALLs, the methylation frequencies (in descending order) were as follows: $57 \%$ for NES-1, $40 \%$ for LATS-1, 37\% for $C D H 1,35 \%$ for $C D H 13,35 \%$ for $p 16,34 \%$ for $A P A F-1,33 \%$ for DKK-3, 29\% for $p 15,27 \%$ for PARKIN, $20 \%$ for PTEN, $18 \%$ for $p 57,18 \%$ for $p 73,13 \%$ for $D A P K, 9 \%$ for $T M S-1$, and $8.5 \%$ for $p 14$ (Table 3). No methylated genes were found in 57 (22.7\%) of 251 patients, whereas most ALLs (194 [77.3\%] of 251) had methylation of at least 1 methylated gene (range, 1-10) (Table 3). No case was found to have methylation of more than 10 genes. According to the number of methylated genes observed in each individual sample, 104 patients $(41.4 \%)$ were included in methylated group A (1 to 3 methylated genes) and 90 (35.9\%) in methylated group B (more than 3 methylated genes). Significant differences were found between methylation profiles in children and adults. LATS-1 $(P=.05), C D H 1(P=.05), p 15(P=.05), p 57(P=.001)$, and p14 $(P=.05)$ genes were more frequently methylated in adult ALL than in childhood ALL (Table 3). Moreover, $82.7 \%$ of adult ALLs showed methylated genes compared with $71.8 \%$ of childhood ALLs $(P=.03)$ (Table 3). Figure 1 illustrates representative examples of the methylation patterns of the most frequently methylated genes.

By analyzing the methylation status of 15 genes simultaneously, we were able to study correlations between their methylation status. Methylation of DKK-3, NES-1, PARKIN, LATS-1, PTEN, p73, p16, p14, CDH1, CDH13, DAPK, and p15 genes were significantly correlated (Table 4). By contrast, methylation of TMS1 and p57 showed no significant correlation with each other or with any of the gene groups mentioned in this paragraph.

\section{Clinical outcome and methylation profile}

As shown in Table 1, clinical and laboratory characteristics did not differ significantly between methylation groups. Poor-risk cytogenetics or molecular events, risk groups according to both NCI and 
Table 3. Methylation profile in ALL

\begin{tabular}{|c|c|c|c|}
\hline Feature & Overall, \% & Childhood ALL, \% & Adult ALL, \% \\
\hline \multicolumn{4}{|l|}{ Methylated genes } \\
\hline NES-1 & 57 & 55 & 58 \\
\hline LATS-1* & 40 & 30 & 47 \\
\hline $\mathrm{CDH} 1^{*}$ & 37 & 32 & 42 \\
\hline $\mathrm{CDH} 13$ & 35 & 32 & 37 \\
\hline p16 & 35 & 32 & 36 \\
\hline$A P A F-1$ & 34 & 35 & 34 \\
\hline$D K K-3$ & 33 & 32 & 33 \\
\hline$p 15^{\star}$ & 29 & 20 & 38 \\
\hline PARKIN & 27 & 30 & 24 \\
\hline PTEN & 20 & 20 & 19 \\
\hline$p 57 \dagger$ & 18 & 2 & 34 \\
\hline$p 73$ & 18 & 18 & 18 \\
\hline$D A P K$ & 13 & 10 & 17 \\
\hline TMS-1 & 9 & 10 & 7 \\
\hline$p 14^{*}$ & 8.5 & 5 & 13 \\
\hline \multicolumn{4}{|l|}{ Methylation group } \\
\hline Nonmethylated $\neq$ & 22.7 & 28.2 & 17.3 \\
\hline Methylated & 77.3 & 71.8 & 82.7 \\
\hline Group A & 41.4 & 38.7 & 44.1 \\
\hline Group B & 35.9 & 33.1 & 38.6 \\
\hline \multicolumn{4}{|c|}{ No. methylated genes } \\
\hline $0^{*}$ & 22.7 & 28.2 & 18.1 \\
\hline 1 & 9.3 & 8.1 & 9.4 \\
\hline 2 & 19.9 & 21 & 18.9 \\
\hline 3 & 12.7 & 9.7 & 15.7 \\
\hline 4 & 10 & 6.5 & 13.4 \\
\hline 5 & 10 & 9.7 & 10.2 \\
\hline 6 & 5.6 & 6.5 & 4.7 \\
\hline 7 & 4.8 & 6.5 & 3.1 \\
\hline 8 & 2 & 1.6 & 2.4 \\
\hline 9 & 1.6 & 1.6 & 1.6 \\
\hline 10 & 1.6 & 0.8 & 2.4 \\
\hline
\end{tabular}

PETHEMA classifications, good risk features (hyperdiploidy and TEL-AML1 fusion), type of PETHEMA protocol administered, and number of patients who received stem cell transplants were distributed similarly among the 3 methylation groups. Separate analysis of adult and childhood ALL patients gave the same results as the global series.

Table 1 details the relapse history, CR rates, and mortality for patients in the different methylation groups. CR rates of patients in the nonmethylated, methylated $\mathrm{A}$, and methylated $\mathrm{B}$ groups were $91 \%, 93 \%$, and $88 \%$, respectively, accounting for $91 \%$ of the overall CR rate. This suggests that the methylation profile did not correlate with response to remission induction therapy. However, patients in the nonmethylated group had a lower rate of relapse than patients in methylated groups A and B (17\% versus $51 \%$ and $59 \%$, respectively, $P<.0001)$. Mortality rate was also lower for the nonmethylated group compared with methylated groups A and B (28\% versus $43 \%$ and $61 \%$, respectively, $P<.001$ ). Similar results were obtained in the separate analyses of children (relapse rate, $14 \%$ for nonmethylated group versus $35 \%$ and $48 \%$ for methylated groups A and $\mathrm{B}$, respectively, $P=.003$; mortality rate, $14 \%$ for nonmethylated group versus $20 \%$ and $37 \%$ for methylated groups $\mathrm{A}$ and $\mathrm{B}$, respectively, $P=.04$ ) and adults (relapse rate, $28 \%$ for nonmethylated group versus $67 \%$ and $68 \%$ for methylated groups A and $\mathrm{B}$, respectively, $P=.002$; mortality rate, $50 \%$ for nonmethylated group versus $63 \%$ and $81 \%$ for methylated groups A and B, respectively, $P=.02$ ).
We analyzed the DFS among patients who achieved CR according to the methylation profile. Estimated DFS rates at 11 years were $75.5 \%$ and $25.6 \%$ for nonmethylated and methylated groups, respectively (group A, 37.2\%; group B, 9.4\%) $(P<.0001)$ (Figure 2A). Among children, the 11-year DFS was $79.7 \%$ for nonmethylated group and $36.5 \%$ for methylated group (group A, $55 \%$; group $\mathrm{B}, 18.6 \% ; P=.001$ ) (Figure $2 \mathrm{~B}$ ). Among adult ALL patients, the 11 -year DFS was $66.5 \%$ for nonmethylated group and $15.6 \%$ for methylated group (group A, 20.4\%; group B, $7.1 \%$; $P=.001$ ) (Figure 2C). The actuarial OS at 12 years calculated for all leukemic patients was $66.1 \%$ for nonmethylated patients and $27.4 \%$ for methylated patients (group A, $45.5 \%$; group B, $7.8 \%$; $P=.0004$ ) (Figure 3A). Significant differences were observed in the actuarial OS among nonmethylated, methylated A, and methylated B groups in the separate analyses of children $(78.1 \%, 75.1 \%$, and $18.1 \%$, respectively, $P=.01$ ) (Figure $3 \mathrm{~B}$ ) and adults (46.6\%, $22.1 \%$ and $4.2 \%$, respectively, $P=.05$ ) (Figure $3 \mathrm{C}$ ).

A multivariate analysis of potential prognostic factors (including the type of PETHEMA protocol applied) demonstrated that hypermethylation profile was an independent prognostic factor in predicting DFS in the global series $(P<.0001)$ as well as in both childhood $(P=.0001)$ and adult ALLs $(P=.006)$ (Table 5). Methylation status was also independently associated with OS in the global series $(P=.003)$ and childhood $\operatorname{ALL}(P=.02)$ (Table 6).

\section{Prognostic impact of the methylation profile in selected risk groups}

To determine the prognostic impact of the methylation profile in selected ALL groups with well-established prognostic factors, we analyzed DFS and OS in TEL-AML1+ and $B C R-A B L^{+}$patients and also in patients with high white blood cell (WBC) count $\left(>50 \times 10^{9} / \mathrm{L}\left[>50000 \mathrm{~mm}^{3}\right]\right)$ at diagnosis. Among TEL-AML1 ${ }^{+}$ children $(\mathrm{n}=44)$, the 8 -year DFS was $87.5 \%$ for the nonmethylated group and $38 \%$ for the methylated group $(P=.04)$ (Figure $4 \mathrm{~A})$. The actuarial OS at 8 years for the same patients was $100 \%$ for nonmethylated patients and $77.4 \%$ for methylated patients $(P=.05)$ (Figure $4 \mathrm{~A})$. Among $B C R-A B L^{+}$patients $(\mathrm{n}=47)$, the 6-year DFS was $67.3 \%$ for nonmethylated patients and $4.1 \%$ for methylated patients $(P=.001)$ (Figure 4B). Estimated 7-year OS was $59.8 \%$ for nonmethylated BCR-ABL patients and $0 \%$ for methylated patients $(P=.02)$ (Figure 4B). Among ALL patients with high WBC count at diagnosis $(\mathrm{n}=73)$, DFS at 9 years was $58.3 \%$ for nonmethylated patients and

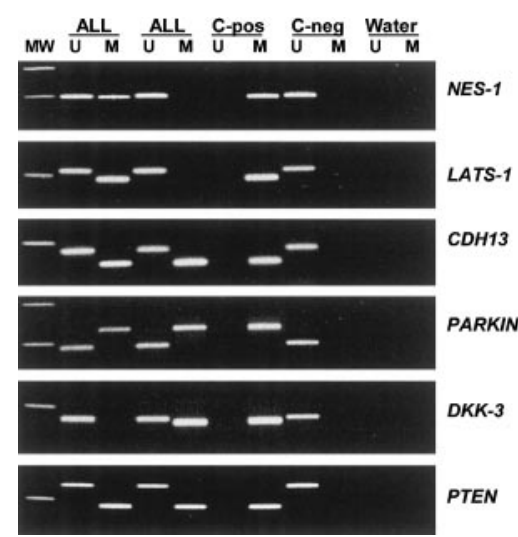

Figure 1. Aberrant promoter methylation of different genes in acute lymphoblastic leukemia. MW indicates molecular weight marker; ALL, acute lymphoblastic leukemia samples; C-pos, human male genomic DNA universally methylated for all genes (used as a positive control for methylated alleles); C-neg, healthy individual water, blank control without DNA added; $\mathrm{U}$, unmethylated alleles; and M, methylated alleles. 
Table 4. Correlations between methylation status of the different genes studied

\begin{tabular}{|c|c|c|c|c|c|c|c|c|c|c|c|c|c|c|c|}
\hline & $N E S$ & $D K K$ & PARKIN & $A P A F$ & LATS & PTEN & $p 57$ & $p 73$ & $p 16$ & $p 14$ & CDH1 & $\mathrm{CDH13}$ & $D A P K$ & $T M S$ & $p 15$ \\
\hline NES & - & - & - & - & - & - & - & - & - & - & - & - & - & - & - \\
\hline$D K K$ & .0001 & - & - & - & - & - & - & - & - & - & - & - & - & - & - \\
\hline PARKIN & .0001 & .0001 & - & - & - & - & - & - & - & - & - & - & - & - & - \\
\hline$A P A F$ & NS & NS & NS & - & - & - & - & - & - & - & - & - & - & - & - \\
\hline LATS & .006 & NS & NS & .0001 & - & - & - & - & - & - & - & - & - & - & - \\
\hline PTEN & .0001 & .0001 & .0001 & NS & NS & - & - & - & - & - & - & - & - & - & - \\
\hline p57 & NS & NS & NS & NS & NS & NS & - & - & - & - & - & - & - & - & - \\
\hline$p 73$ & NS & NS & NS & NS & NS & .001 & NS & - & - & - & - & - & - & - & - \\
\hline$p 16$ & .001 & NS & NS & NS & NS & NS & NS & .0001 & - & - & - & - & - & - & - \\
\hline p14 & NS & .005 & NS & NS & NS & NS & NS & NS & NS & - & - & - & - & - & - \\
\hline $\mathrm{CDH} 1$ & .0001 & .0001 & .0001 & NS & NS & .0001 & NS & NS & NS & NS & - & - & - & - & - \\
\hline $\mathrm{CDH} 13$ & .0001 & .0001 & .0001 & NS & .001 & .0001 & NS & NS & NS & .0001 & .0001 & - & - & - & - \\
\hline$D A P K$ & NS & NS & NS & NS & NS & NS & NS & NS & NS & NS & .0001 & .0001 & - & - & - \\
\hline TMS & NS & NS & NS & NS & NS & NS & NS & NS & NS & NS & NS & NS & NS & - & - \\
\hline$p 15$ & .003 & .0001 & .0001 & NS & NS & .002 & .002 & .004 & .001 & NS & .0001 & .0001 & NS & NS & - \\
\hline
\end{tabular}

—indicates already performed; and NS, nonsignificant.

$11.5 \%$ for methylated patients $(P=.07)$ (Figure 4C). No significant difference was observed in OS in these patients.

\section{Discussion}

Epigenetic gene silencing is increasingly being recognized as a common way in which cancer cells inactivate cancer-related genes. ${ }^{4-8}$ Attention has focused on the methylation of regions in the genome that might have functional significance resulting from the

\section{A}
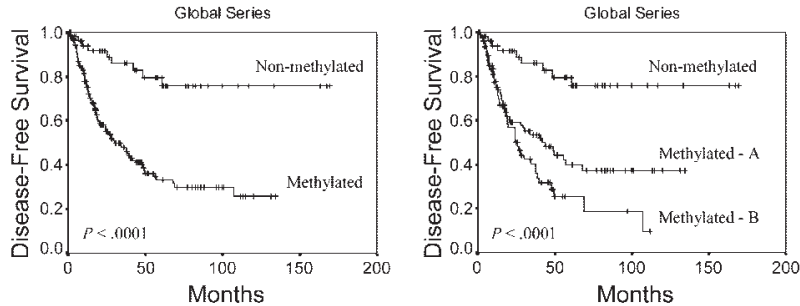

B
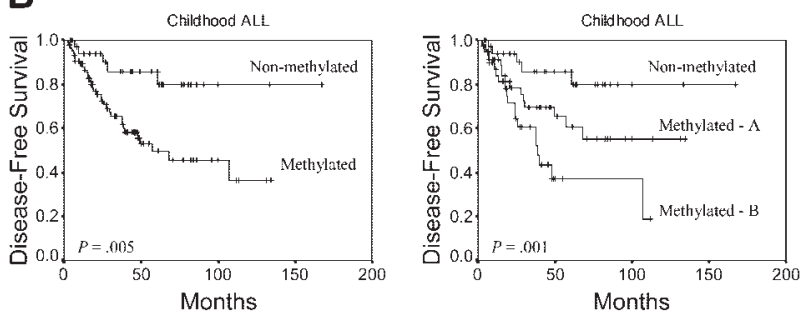

C
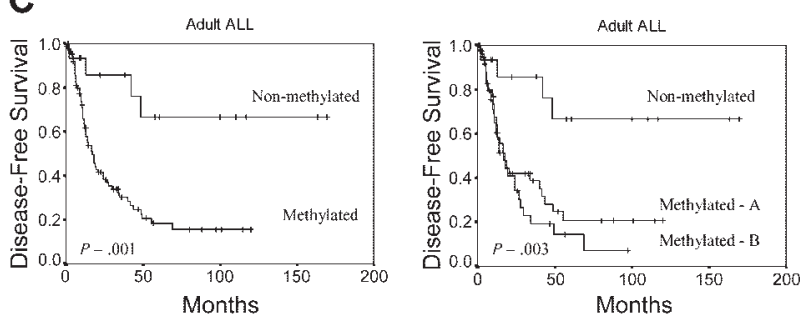

Figure 2. Kaplan-Meier survivor function for ALL patients. DFS curves according to the methylation profile. Methylated group $A$ indicates patients with 1 to 3 methylated genes; and methylated group $B$, patients with more than 3 methylated genes. (A) All patients enrolled in this study. (B) Childhood ALL. (C) Adult ALL. extinction of gene activity. Whereas most individual cancers have several, perhaps hundreds, of methylated genes (a phenomenon termed $\mathrm{CpG}$ island methylator phenotype), ${ }^{35}$ the methylation profiles of individual tumor types are characteristic of this type of cancer. However, there is relatively modest information on this profiling in ALL. ${ }^{13-15}$ Our results indicate that methylation of multiple genes is a common phenomenon in ALL and may be the most important way to inactivate cancer-related genes in this disease; $77.3 \%$ of cases had at least 1 gene methylated, whereas $35.9 \%$ of cases had 4 or more genes methylated. Significant differences were found in the methylation profiles of childhood and
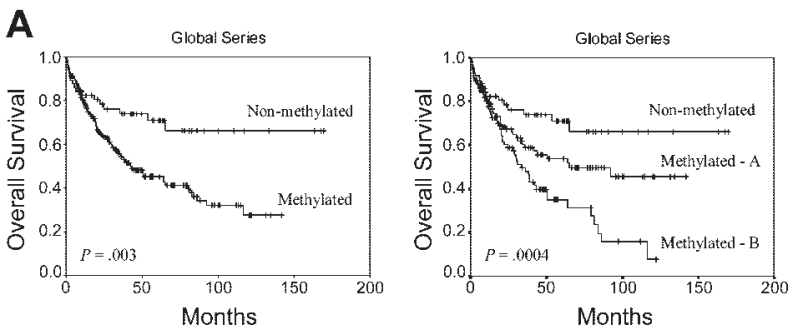

B
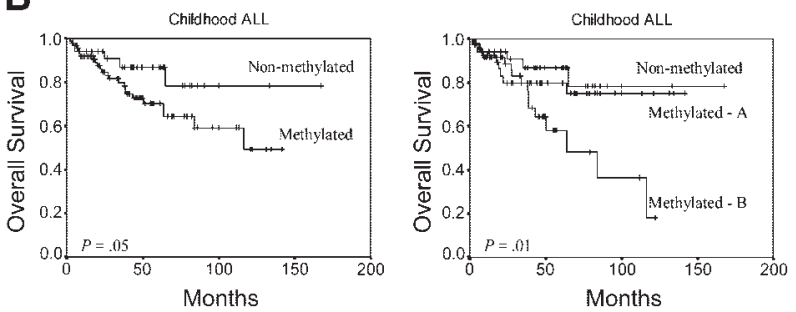

C


Figure 3. Kaplan-Meier survivor function for ALL patients. OS curves according to the methylation profile. Methylated A indicates patients with 1 to 3 methylated genes; and methylated $B$, patients with more than 3 methylated genes. (A) All patients enrolled in this study. (B) Childhood ALL. (C) Adult ALL. 
Table 5. Multivariate Cox model for disease-free survival

\begin{tabular}{lcc}
\multicolumn{1}{c}{ Feature } & Univariate analysis $\boldsymbol{P}$ & Multivariate analysis $\boldsymbol{P}$ \\
\hline Global series & & \\
Methylation profile & $<.0001$ & \\
WBC count higher than & & .0001 \\
$50 \times 10^{9} / \mathrm{L}$ & .0002 & .01 \\
$B C R-A B L$ positivity & .004 & - \\
T phenotype & .03 & - \\
Age older than 15 years & .007 & - \\
PETHEMA poor risk & .04 & .0001 \\
Childhood ALL & & .05 \\
Methylation profile & .0001 & - \\
PETHEMA poor risk & .05 & - \\
WBC count higher than & & \\
$50 \times 10^{9} / \mathrm{L}$ & .05 & .001 \\
NCI poor risk & .05 & .006 \\
Adult ALL & & .02 \\
BCR-ABL positivity & .0001 & \\
Methylation profile & .003 & \\
WBC higher than $50 \times 10^{9} / \mathrm{L}$ & .0002 & \\
\hline
\end{tabular}

— indicates not significant.

adult ALLs, suggesting that methylation status in ALL is age related. Adult ALL patients showed more frequent methylation of LATS-1, CDH1, p15, p57, and $p 14$ genes and also a higher number of simultaneously methylated genes than childhood ALL patients. It is well known that prognosis of children with ALL is significantly superior to that of adults, even if they are matched for poor prognosis features; our results suggest that this different epigenetic map may have a role in explaining the prognostic differences in the 2 age groups. Furthermore, methylation of several of the genes analyzed here was strongly correlated, suggesting that $\mathrm{CpG}$ island methylation is related to specific methylation defects in subsets of ALLs, rather than that methylation of each individual island represents a random event followed by selection for the affected cell.

Our data also show that the methylation in human ALL cells can participate in the inactivation of 3 key cellular pathways:

1. growth-deregulating events comprising events that target the principal late- $\mathrm{G}_{1}$ cell cycle checkpoint either directly $(p 15, p 16$,

Table 6. Multivariate Cox model for overall survival

\begin{tabular}{lcc}
\hline \multicolumn{1}{c}{ Feature } & Univariate analysis $\boldsymbol{P}$ & Multivariate analysis $\boldsymbol{P}$ \\
\hline Global series & & \\
WBC count higher than & $<.0001$ & $<.0001$ \\
$50 \times 10^{9} / \mathrm{L}$ & .0005 & .003 \\
Methylation profile & $<.0001$ & .01 \\
PETHEMA poor risk & $<.0001$ & .05 \\
Age older than 15 years & .0003 & - \\
BCR-ABL positivity & .005 & - \\
T phenotype & & .005 \\
Childhood ALL & .005 & .02 \\
T phenotype & .03 & - \\
Methylation profile & & - \\
WBC count higher than & .05 & \\
$50 \times 10^{9} / \mathrm{L}$ & .05 & .0001 \\
NCl poor risk & & - \\
Adult ALL & .0001 & \\
WBC count higher than & .001 & \\
$50 \times 10^{9} / \mathrm{L}$ & .03 & \\
$B C R-A B L$ positivity & & \\
Methylation profile & & \\
\hline
\end{tabular}

See Table 5 footnote for abbreviations.
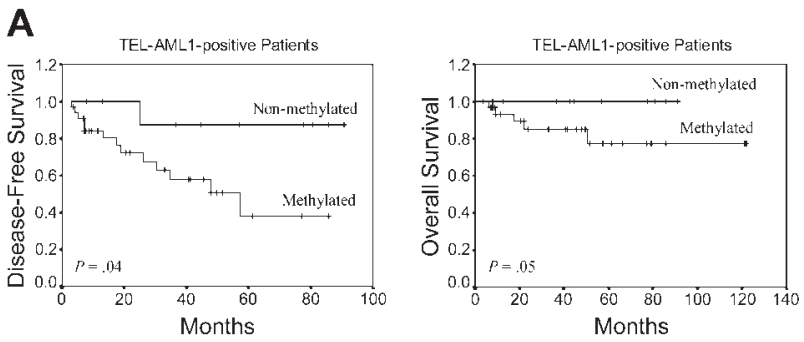

B
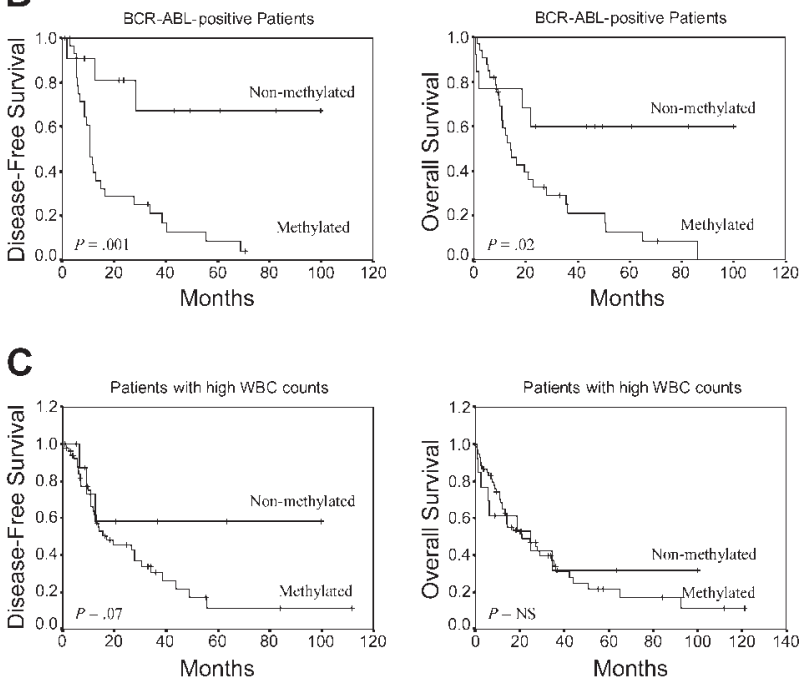

Figure 4. Kaplan-Meier survivor function for selected prognostic groups of $A L L$ patients. DFS and OS curves according to the methylation profile. (A) TEL-AML1+ ALL patients. (B) $B C R-A B L^{+}$ALL patients. (C) Patients with high WBC count at diagnosis.

and p57 inactivation) or indirectly ( $p 73$, PTEN, and NES-1 inactivation) and events that regulate the $\mathrm{G}_{2}-\mathrm{M}$ transition downregulating $\mathrm{CDC} 2 /$ cyclin A kinase activity (LATS-1) and those that antagonize the WNT/beta-catenin oncogenic signaling pathway $(D K K-3)$;

2. the apoptotic program through inactivation of $p 14, T M S 1$, $A P A F-1$, and $D A P K$; and

3. the cell-cell adhesion by the inactivation of some members of the cadherin family ( $\mathrm{CDH} 13$ and $\mathrm{CDH1}$ ), which are more than simply a "sticky molecular complex" because they have the ability to inhibit cell proliferation by the up-regulation of $p 27$ (another $\mathrm{G}_{1}$ checkpoint gene) and because their down-regulation also interferes with apoptotic signals putting the affected cell into a state of de facto anoikis. ${ }^{36}$

All these abnormalities are not surprising. Beneath the complexity and idiopathy of every cancer lies a limited number of "mission-critical" events that have propelled the tumor cell and its progeny into uncontrolled expansion and invasion. One of these is deregulated cell proliferation, which, together with the compensatory suppression of apoptosis needed to support it, provides a minimal "platform" necessary to support further neoplastic progression. ${ }^{37}$ Our data show that in ALL this common platform can be achieved by a methylation mechanism. Interestingly, although genetic abnormalities of key tumor-suppressor genes such as $R B$ and, especially, p53 are the most common molecular lesions in human cancer, ${ }^{38}$ they are relatively less frequent in de novo ALL. ${ }^{3}$ In view of our results, one hypothesis is that the methylation of 
cytosine nucleotides in ALL cells can help inactivate (1) tumorsuppressive apoptotic or growth-arresting responses by deregulation of the cyclin-dependent kinases that phosphorylate and functionally inactive retinoblastoma (RB) protein (at the $p 15, p 16$, and $p 57$ level) and either upstream (at $p 14$ or $D A P K$ ) or downstream (APAF-1) of $p 53$ and also (2) $p 73$, which encodes for a protein that is both structurally and functionally homologous to the p53 protein. ${ }^{39}$ This implies that in ALL too there is a strong selection for tumor cells to lose critical tumor-suppressor gene functions (not only p53 and RB but also LATS-1 and PTEN) but, in this case, indirectly through an alternative epigenetic way.

In this study, we have shown that aberrant methylation of $\mathrm{CpG}$ islands is quantitatively different in individual tumors within the same tumor type and that this patient-specific methylation profile provides important prognostic information in ALL patients. The presence in individual tumors of multiple epigenetic events that affect each of the pathways we have discussed is a factor of poor prognosis in both childhood and adult ALL. Patients with methylation of 4 or more genes had a poorer DFS and OS than patients with 3 or fewer methylated genes or patients lacking promoter hypermethylation. Multivariate analysis confirmed that methylation profile was associated with a shorter DFS and OS. Moreover, methylation status was able to redefine the prognosis of selected ALL groups with well-established prognostic features. Lack of promoter methylation improved the generally poor outcome of patients presenting Philadelphia chromosome or high WBC count at diagnosis, whereas the presence of methylation worsened the generally good outcome of TEL-AML1 ${ }^{+}$patients. Therefore, methylation profiling in ALL could have important clinical implications, complementing standard immunophenotypic, cytogenetic, and molecular studies for guiding the selection of therapy and also providing a basis for developing novel therapies, such as demethylation treatment.

In summary, our results indicate that simultaneously aberrant methylation affecting key molecular pathways is a common phenomenon in ALL. The methylation profile seems to be an important factor in predicting the clinical outcome of ALL patients.

\section{References}

1. Pui C-H, Evans WE. Acute lymphoblastic leukemia. N Engl J Med. 1998;339:605-615

2. Faderl S, Kantarjian HM, Talpaz M, Estrov Z. Clinical significance of cytogenetic abnormalities in adult acute lymphoblastic leukemia. Blood. 1998;91:3995-4019.

3. Wada M, Bartram CR, Nakamura $\mathrm{H}$, et al. Analysis of p53 mutations in a large series of lymphoid hematologic malignancies of childhood. Blood. 1993;82:3163-3169.

4. Bird A. DNA methylation patterns and epigenetic memory. Genes Dev. 2002;16:6-21.

5. Jones PA, Baylin SB. The fundamental role of epigenetic events in cancer. Nat Rev. 2002;3: 415-428.

6. Herman JG, Baylin SB. Gene silencing in cancer in association with promoter hypermethylation. N Engl J Med. 2003;349:2042-2054

7. Costello JF, Fruhwald MC, Smiraglia DJ, et al. Aberrant CpG-island methylation has non-random and tumour-type-specific patterns. Nat Genet. 2000;24:132-138

8. Esteller M, Corn PG, Baylin SB, Herman JG. A gene hypermethylation profile of human cancer. Cancer Res. 2001;61:3225-3229.

9. Kawano S, Miller CW, Gombart AF, et al. Loss of p73 gene expression in leukemias/lymphomas due to hypermethylation. Blood. 1999;94:1113 1120.

10. Melki JR, Vincent PC, Brown RD, Clark SJ. Hypermethylation of E-cadherin in leukemia. Blood 2000;95:3208-3213.

11. Wong $\mathrm{IH}, \mathrm{Ng} \mathrm{MH}$, Huang DP, Lee JC. Aberrant p15 promoter methylation in adult and childhood acute leukemias of nearly all morphologic subtypes: potential prognostic implications. Blood. 2000;95:1942-1949.

12. Roman-Gomez J, Castillejo JA, Jimenez A, et al Hypermethylation of the calcitonin gene in acute lymphoblastic leukaemia is associated with unfavourable clinical outcome. Br J Haematol. 2001; 113:329-338.

13. Garcia-Manero G, Daniel J, Smith TL, et al. DNA methylation of multiple promoter-associated $\mathrm{CpG}$ islands in adult acute lymphoblastic leukemia. Clin Cancer Res. 2002;8:2217-2224.

14. Roman-Gomez J, Castillejo JA, Jimenez A, et al. $5^{\prime} \mathrm{CpG}$ island hypermethylation is associated with transcriptional silencing of the p21 cip1/waf1/ sdi1 gene and confers poor prognosis in acute lymphoblastic leukemia. Blood. 2002;99:22912296.
15. Shen L, Toyota M, Kondo Y, et al. Aberrant DNA methylation of p57KIP2 identifies a cell-cycle regulatory pathway with prognostic impact in adult acute lymphocytic leukemia. Blood. 2003; 101:4131-4136.

16. Smith M, Arthur D, Camitta B, et al. Uniform approach to risk classification and treatment assignment for children with acute lymphoblastic leukemia. J Clin Oncol. 1996;14:18-24.

17. Ortega JJ. Spanish acute lymphoblastic leukemia trials. Int J Pediat Hemat Oncol. 1998;5:163-176.

18. Ribera JM, Ortega JJ, Oriol A, et al. Prognostic value of karyotypic analysis in children and adults with high-risk acute lymphoblastic leukemia included in the PETHEMA ALL-93 trial. Haematologica. 2002;87:154-166

19. Ribera JM, Ortega JJ, Oriol A, et al. Late intensification chemotherapy has not improved the results of intensive chemotherapy in adult acute lymphoblastic leukemia: results of a prospective multicenter randomized trial (PETHEMA ALL-89). Haematologica. 1998;83:222-230.

20. Ortega JJ, Ribera JM, Oriol A, et al. Early and delayed consolidation chemotherapy significantly improves the outcome of children with intermediate-risk acute lymphoblastic leukemia: final results of the prospective randomized PETHEMA ALL-89 TRIAL. Haematologica. 2001;86:586-595.

21. Roman-Gomez J, Jimenez-Velasco A, Agirre X, et al. The normal epithelial cell-specific 1 (NES1) gene, a candidate tumor suppressor gene on chromosome 19q13.3-4, is down-regulated by hypermethylation in acute lymphoblastic leukemia. Leukemia. 2004;18:362-365.

22. Roman-Gomez J, Jimenez-Velasco A, Agirre X, et al. Transcriptional silencing of the Dickkopfs-3 (Dkk-3) gene by $\mathrm{CpG}$ hypermethylation in acute lymphoblastic leukaemia. Br J Cancer. 2004;91: 707-713.

23. Roman-Gomez J, Castillejo JA, Jimenez A, et al Cadherin-13, a mediator of calcium-dependent cell-cell adhesion, is silenced by methylation in chronic myeloid leukemia and correlates with pretreatment risk profile and cytogenetic response to interferon-alfa. J Clin Oncol. 2003;21:1472-1479.

24. Esteller M, Tortola S, Toyota M, et al. Hypermethylation-associated inactivation of $\mathrm{p} 14$ is independent of p16 methylation and p53 mutational status. Cancer Res. 2000;60:129-133.

25. Conway KE, McConnell BB, Bowring CE, Donald CD, Warren ST, Vertino PM. TMS1, a novel proapoptotic caspase recruitment domain protein, is a target of methylation-induced gene silencing in human breast cancer. Cancer Res. 2000;60: 6236-6242.

26. Fu WN, Bertoni F, Kelsey SM, et al. Role of DNA methylation in the suppression of Apaf-1 protein in human leukaemia. Oncogene. 2003;22:451-455.

27. Katzenellenbogen RA, Baylin SB, Herman JG. Hypermethylation of the DAP-kinase $\mathrm{CpG}$ island is a common alteration in B-cell malignancies. Blood. 1999;93:4347-4353.

28. Cesari R, Martin ES, Calin GA, et al. Parkin, a gene implicated in autosomal recessive juvenile parkinsonism, is a candidate tumor suppressor gene on chromosome 6q25-q27. Proc Natl Acad Sci U S A. 2003:100:5956-5961.

29. Hisaoka M, Tanaka A, Hashimoto H. Molecular alterations of h-warts/LATS1 tumor suppressor in human soft tissue sarcoma. Lab Invest. 2002;82: 1427-1435.

30. Zysman MA, Chapman WB, Bapat B. Considerations when analyzing the methylation status of PTEN tumor suppressor gene. Am J Pathol. 2002;160:795-800.

31. Takeuchi S, Bartram CR, Wada M, et al. Allelotype analysis of childhood acute lymphoblastic leukemia. Cancer Res. 1995;55:5377-5382.

32. Herman JG, Graff JR, Myohanen S, Nelkin BD, Baylin SB. Methylation-specific PCR: a novel PCR assay for methylation status of $\mathrm{CpG}$ islands. Proc Natl Acad Sci U S A. 1996; 93: 9821-9826.

33. Cimino G, Rapanotti MC, Rivolta A, et al. Prognostic relevance of ALL-1 gene rearrangement in infant acute leukemias. Leukemia. 1995:9:391-395.

34. van Dongen JJM, Macintyre EA, Gabert JA, et al. Standardized RT-PCR analysis of fusion gene transcripts from chromosome aberrations in acute leukemia for detection of minimal residual disease. Leukemia. 1999;13:1901-1928.

35. Toyota M, Ahuja N, Ohe-Toyota M, Herman JG, Baylin SB, Issa JP. CpG island methylator phenotype in colorectal cancer. Proc Natl Acad Sci U S A. 1999;96:8681-8686.

36. Wijnhoven BPL, Dinjens WNM, Pignatelli M. Ecadherin-catenin cell-cell adhesion complex and human cancer. Br J Surg. 2000;87:992-1005.

37. Evan GI, Vousden KH. Proliferation, cell cycle and apoptosis in cancer. Nature. 2001;411:342348.

38. Woods DB, Vousden KH. Regulation of p53 function. Exp Cell Res. 2001;264:56-66

39. Irwin MS, Kaelin WG. P53 family update. p73 and p63 develop their own identities. Cell Growth Differ. 2001;12:337-349. 